\title{
Freezing Nitrogen Ethanol Composite May be a Viable Approach for Cryotherapy of Human Giant Cell Tumor of Bone
}

\author{
Po-Kuei Wu MD, Cheng-Fong Chen MD, Jir-You Wang PhD, \\ Paul Chih-Hsueh Chen MD, Ming-Chau Chang MD, Shih-Chieh Hung MD, PhD, \\ Wei-Ming Chen MD
}

Received: 25 August 2016/Accepted: 6 January 2017/Published online: 14 February 2017

(C) The Association of Bone and Joint Surgeons (B) 2017

\begin{abstract}
Background Liquid nitrogen has been used as adjuvant cryotherapy for treating giant cell tumor (GCT) of bone. However, the liquid phase and ultrafreezing $\left(-196^{\circ} \mathrm{C}\right)$ properties increase the risk of damage to the adjacent tissues and may lead to perioperative complications. A novel semisolid cryogen, freezing nitrogen ethanol composite, might mitigate these shortcomings because of less-extreme freezing. We therefore wished to evaluate freezing nitrogen ethanol composite as a coolant to determine its properties in tumor cryoablation.
\end{abstract}

Funding for this study (W-MC) was provided by the Ministry of Science and Technology, Taiwan, ROC.

All ICMJE Conflict of Interest Forms for authors and Clinical Orthopaedics and Related Research ${ }^{\circledR}$ editors and board members are on file with the publication and can be viewed on request.

Clinical Orthopaedics and Related Research ${ }^{\mathbb{R}}$ neither advocates nor endorses the use of any treatment, drug, or device. Readers are encouraged to always seek additional information, including FDAapproval status, of any drug or device prior to clinical use.

Each author certifies that his or her institution approved the human protocol for this investigation, that all investigations were conducted in conformity with ethical principles of research, and that informed consent for participation in the study was obtained.

This work was performed at Taipei Veterans General Hospital,

Taipei, Taiwan.

Electronic supplementary material The online version of this article (doi:10.1007/s11999-017-5239-3) contains supplementary material, which is available to authorized users.

P.-K. Wu, C.-F. Chen

Institute of Clinical Medicine, School of Medicine, National

Yang-Ming University, Taipei, Taiwan

P.-K. Wu, C.-F. Chen, J.-Y. Wang, W.-M. Chen

Department of Orthopaedics, Therapeutical and Research Center of Musculoskeletal Tumor, Taipei Veterans General Hospital,

Taipei, Taiwan
Questions/purposes (1) Is freezing nitrogen ethanol composite-mediated freezing effective for tumor cryoablation in an ex vivo model, and if yes, is apoptosis involved in the tumor-killing mechanism? (2) Does freezing nitrogen ethanol composite treatment block neovascularization and neoplastic progression of the grafted GCTs and is it comparable to that of liquid nitrogen in an in vivo chicken model? (3) Can use of freezing nitrogen ethanol composite as an adjuvant to curettage result in successful short-term treatment, defined as absence of GCT recurrence at a minimum of 1 year in a small proof-of-concept clinical series?

Methods The cryogenic effect on bone tissue mediated by freezing nitrogen ethanol composite and liquid nitrogen was verified by thermal measurement in a time-course manner. Cryoablation on human GCT tissue was examined ex vivo for effect on morphologic features (cell shrinkage) and DNA fragmentation (apoptosis). The presumed mechanism was investigated by molecular analysis of apoptosis regulatory proteins including caspases 3, 8, and 9 and $\mathrm{Bax} / \mathrm{Bcl}-2$. Chicken chorioallantoic membrane was used as an in vivo model to evaluate the effects of freezing nitrogen ethanol composite and liquid nitrogen treatment on GCT-derived neovascularization and tumor neoplasm. A small group of patients with GCT of bone was treated by curettage and adjuvant freezing nitrogen ethanol composite cryotherapy in a proof-of-concept study. Tumor recurrence

\footnotetext{
P.-K. Wu, C.-F. Chen, J.-Y. Wang, M.-C. Chang,

W.-M. Chen ( $\triangle)$

Department of Orthopaedics \& Traumatology, Taipei Veterans General Hospital, 201, Sec 2, Shih-Pai Road, Taipei 112, Taiwan e-mail: wmchen2499@gmail.com
} 
and perioperative complications were evaluated at a minimum of 19 months followup (mean, 24 months; range, 19-30 months).

Results Freshly prepared freezing nitrogen ethanol composite froze to $-136^{\circ} \mathrm{C}$ and achieved $-122^{\circ} \mathrm{C}$ isotherm across a piece of $10 \pm 0.50$-mm-thick bone with a freezing rate of $-34^{\circ} \mathrm{C}$ per minute, a temperature expected to meet clinical tumor-killing requirements. Human GCT tissues revealed histologic changes including shrinkage in morphologic features of multinucleated giant cells in the liquid nitrogen $(202 \pm 45 \mu \mathrm{m} ; \mathrm{p}=0.006)$ and freezing nitrogen ethanol composite groups (169 $\pm 27.4 \mu \mathrm{m} ; \mathrm{p}<0.001)$, and a decreased nucleated area of neoplastic stromal cells for the 30-second treatment. Enhanced counts of terminal deoxynucleotidyl transferase dUTP nick end labeling (TUNEL)-positive cells verified the involvement of DNA fragmentation in cryoablated GCT tissues. Western blotting analysis on the expression of apoptosis regulatory proteins showed enhancement of proteocleavage-activated caspases 3, 8, and 9 and higher ratios of $\mathrm{Bax} / \mathrm{Bcl} 2$ in the liquid nitrogen- and freezing nitrogen ethanol compositetreated samples. Numbers of blood vessels and human origin tumor cells also were decreased by freezing nitrogen ethanol composite and liquid nitrogen treatment in the GCT-grafted chicken chorioallantoic membrane model. Seven patients with GCT treated by curettage and adjuvant cryotherapy by use of freezing nitrogen ethanol composite preparation had no intra- or postoperative complications related to the freezing, and no recurrences during the study surveillance period.

Conclusions These preliminary in vitro and clinical findings suggest that freezing nitrogen ethanol composite may be an effective cryogen showing ex vivo and in vivo tumor cryoablation comparable to liquid nitrogen. The semisolid phase and proper thermal conduction might avoid some of the disadvantages of liquid nitrogen in cryotherapy, but a larger clinical study is needed to confirm these findings.

P. C.-H. Chen

Department of Pathology and Laboratory Medicine, Taipei

Veterans General Hospital, Taipei, Taiwan

J.-Y. Wang

Institute of Traditional Medicine, School of Medicine, National

Yang-Ming University, Taipei, Taiwan

P.-K. Wu, C.-F. Chen, M.-C. Chang, W.-M. Chen

Department of Orthopedics, School of Medicine, National Yang-

Ming University, Taipei, Taiwan

S.-C. Hung

Integrative Stem Cell Center, China Medical University Hospital, Institute of Clinical Medicine, China Medical

University, Taichung, Taiwan
Level of evidence Level IV, therapeutic study.

\section{Introduction}

Giant cell tumor (GCT) of bone is an aggressive benign tumor accounting for $5 \%$ and $20 \%$ of primary bone tumors in Western and Chinese populations respectively [1, 2, 4, 31]. Extended intralesional curettage, which includes high-speed burring, is the primary treatment option for many patients with GCT. With such treatment, however, local recurrence is relatively frequent, with reported incidences as much as $12 \%-50 \%[14,15,28]$. To decrease the risk of postcurettage recurrence, several types of local adjuvant treatments, such as use of polymethylmethacrylate, phenol, or liquid nitrogen, have been considered [10,11, 14, 19, 20, 24]. Since the 1960 s, cryotherapy by use of liquid nitrogen as the cryogenic source has been used in adjuvant treatment of some musculoskeletal tumors, including GCT, and showed that it is useful in reducing recurrence but is associated with complications related to the freezing [17, 18, 22, 23, 29, 37, 39].

The mechanisms of cryoablation-mediated cell death have been studied [6, 12, 13, 27, 37]. In brief, rapid freezing induces intracellular ice crystallization and propagation of ice mediates mechanical stress, which causes damage to cellular organelles. The resulting ice recrystallization is accompanied by slow thawing that mediates further damaging stress. To achieve a promising lethal effect on tumor cells, minimum intracellular freezing of $-50^{\circ} \mathrm{C}$ to $-70^{\circ} \mathrm{C}$ and a freezing rate greater than $-20^{\circ} \mathrm{C}$ per minute are advised [5]. In addition, thawing slower than $10^{\circ} \mathrm{C}$ per minute is required $[7,8,37]$. The ultimate goal is to eradicate tumor cells without damage to the adjacent healthy tissues. Directly pouring a cryogenic source such as liquid nitrogen into the surgical bone cavity was first introduced by Marcove [17] and Marcove et al. $[18,19]$, and was reported to be an effective procedure. As a result of easy accessibility and cost-effectiveness, Marcove's method remains the standard procedure for adjuvant cryotherapy in the treatment of certain aggressive but benign or low-grade bone tumors. However, this treatment is associated with local complications like fracture in as many as $42 \%$ of patients [23]; less commonly, skin necrosis and nerve palsy have been reported [37]. These problems have caused investigators to question the merits of this approach [2, 23, 37]. Complications of liquid nitrogen treatment may be caused directly by spills or overflow of the liquid, or by liquid nitrogen's profound freezing effect $\left(-196^{\circ} \mathrm{C}\right)$ damaging the adjacent normal tissues. To avoid some of the disadvantages associated with the use of directly pouring liquid nitrogen into a tumor cavity after curettage, we explored the development of a novel cryogenic material, freezing nitrogen ethanol 
composite, which exhibits similar cooling effects in a semisolid phase, thus avoiding the need to pour the freezing liquid into the surgical field.

Specifically, we asked the following questions: (1) Is freezing nitrogen ethanol composite-mediated freezing effective for tumor cryoablation in an ex vivo model, and if yes, is apoptosis involved in the tumor-killing mechanism? (2) Does freezing nitrogen ethanol composite treatment block neovascularization and neoplastic progression of the grafted GCT and is it comparable to that of liquid nitrogen in an in vivo chicken model? (3) Can use of freezing nitrogen ethanol composite as an adjuvant to curettage, result in successful short-term treatment, defined as absence of GCT recurrence at a minimum of 1 year in a small proof-of-concept clinical series?

\section{Materials and Methods}

Semisolid freezing nitrogen ethanol composite was freshly prepared by mixing ethanol and liquid nitrogen in a ratio of 1:3 before use (Fig. 1) (Video 1. Supplemental materials are available with the online version of $C O R R^{\circledR}$.).

To verify the freezing temperature over the surface directly contacting the liquid nitrogen or freezing nitrogen ethanol composite, measurement was conducted by immersing a calibrated thermocouple in the liquid nitrogen and freezing nitrogen ethanol composite preparation (Fig. 2). To show the isothermal conduction across bone tissue, a thermocouple was introduced into the cavity center of a piece of porcine bone tissue $(10 \pm 0.50 \mathrm{~mm}$ thick; $2 \pm 0.27 \mathrm{~mm}$ cortical; and $8 \pm 0.46 \mathrm{~mm}$ cancellous). Entirely liquid nitrogen- or freezing nitrogen ethanol composite-embedded tissues were verified (Fig. 2C). The temperature was recorded every 30 seconds and the final time was reached at 10 minutes. The cooling rate was determined by dividing the temperature difference between room temperature and the target temperature $\left(-60^{\circ} \mathrm{C}\right)$ by the required cooling time in minutes. Reference freezing parameters effectively lethal to tumor cells were plotted (green) in accordance with prior work [7]. A freezing rate of $-20^{\circ} \mathrm{C}$ per minute has been associated with cellular dehydration and intracellular ice crystallization [7, 8].

With the approval of the institutional review board, the cryoablation mediated on human GCT tissue was further compared between the treatments of freezing nitrogen ethanol composite preparation and liquid nitrogen. The GCT tissue was freshly collected from three patients and then cut into a $1-\mathrm{cm}^{3}$ block. Three experiment groups were respectively exposed to ethanol (ethanol 30 seconds and ethanol 5 minutes), liquid nitrogen (liquid nitrogen 30 seconds and liquid nitrogen 5 minutes), and freezing nitrogen ethanol composite (freezing nitrogen ethanol composite 30 seconds and freezing nitrogen ethanol composite 5 minutes) for two times, followed by 15 minutes of thawing. No treatment was the negative control.

To identify the histologic changes mediated by freezing nitrogen ethanol composite or liquid nitrogen treatment, the standard protocol for preparing hematoxylin and eosin staining was used. To quantitate the effectiveness of cryotreatment on tumor cells, the nucleated area of tumor stromal cells under microscopic observation $(\times 100)$ was characterized and calculated using GraphPad Prism 6 software (Graph Pad Software, La Jolla, CA, USA). The cellular length of multinucleated osteoclast-like giant cells also was measured. Multiple pairwise data comparing intergroup differences were examined by one-way ANOVA and the multiple comparisons were calculated by Bonferroni correction (post hoc test).

Genomic DNA fragmentation resulting from an apoptotic signaling cascade can be detected by staining on the DNA nick-recognizing enzyme, terminal deoxynucleotidyl transferase (TdT). A standard method, terminal deoxynucleotidyl transferase-mediated dUTP-biotin nick labeling (TUNEL), can be used for quantitative measurement on apoptotic cells exhibiting DNA fragmentation. A generally accepted protocol has been reported [26]. Branded kits are commercially available for ensuring the consistency of the TUNEL assay. In the current study, the procedures of the TUNEL assay were done as per the instruction manual available from the In Situ Cell Death Detection kit (POD; Roche, Basel, Switzerland), followed by microscopic counting $(\times 400)$.

The levels of proteins involved in the signaling cascade that regulate programmed cell death were examined by Western blotting assay. The levels of three critical regulatory proteins including caspases 3, 8, and 9 and their inactive precursors were analyzed. Whole cell proteins were extracted for study and Western blotting assay was performed as the standard procedure. Chemiluminescence was detected by using the UVP BioSpectrum ${ }^{\circledR} 600$ Image System $^{\mathrm{TM}}$ (UVP LLC, Upland, CA, USA).

Chicken embryo chorioallantoic membrane assay is a well-established in vivo model to examine the angiogenesis along with tumor progression. The reliability of the chicken chorioallantoic membrane model has been validated for investigation of the progression and invasiveness of human GCT [32]. It also has been affirmed that rapid self-renewing human multipotent mesenchymal bone marrow stromal cells actively adhere to arterial endothelium in a chicken chorioallantoic membrane model [3, 21]. In particular, the chicken chorioallantoic membrane model has been used for evaluating the efficacy of pharmacologic treatment on GCTs by determining the level of angiogenesis [32]. In the current study, we used a previously published method $[3,16,32]$ to develop tumor nodules in 
Fig. 1A-H The diagram shows intralesional curettage in combination with adjuvant cryotherapy by either directly pouring liquid nitrogen or freezing nitrogen ethanol composite (FNEC) preparation. (A) A giant cell tumor is diagnosed in the distal femur. (B) Intralesional excision and high-speed burring are done to remove the visible gross tumor. (C) The residual tumor mass is frequently resistant to removal in the indicated areas: *the roof of the bone cavity shields the residual mass from the surgeon's vision; **residual tumor mass is retained owing to incomplete burring arising from extended cortical bone thinning of the pending fracture area; ***residual tumor mass arises from incomplete burring resulting from dependent articular penetration in the subchondral bone area; ****residual tumor mass segregated from normal bone tissue is invisible in the discontinuous area. (D) Directly pouring liquid nitrogen increases the risk of spillage or overflow of the boiling liquid nitrogen that may injure the adjacent tissue. (E) Semisolid freezing nitrogen ethanol composite is easily scooped to block the bone cavity. The risk arising from handling the boiling liquid nitrogen can be avoided. (F) Slow thawing is done after the freezing procedure. (G) Reconstruction is performed by use of bone grafts and internal fixation after the adjuvant cryotherapy. (H) The freshly prepared semisolid freezing nitrogen ethanol composite is shown.
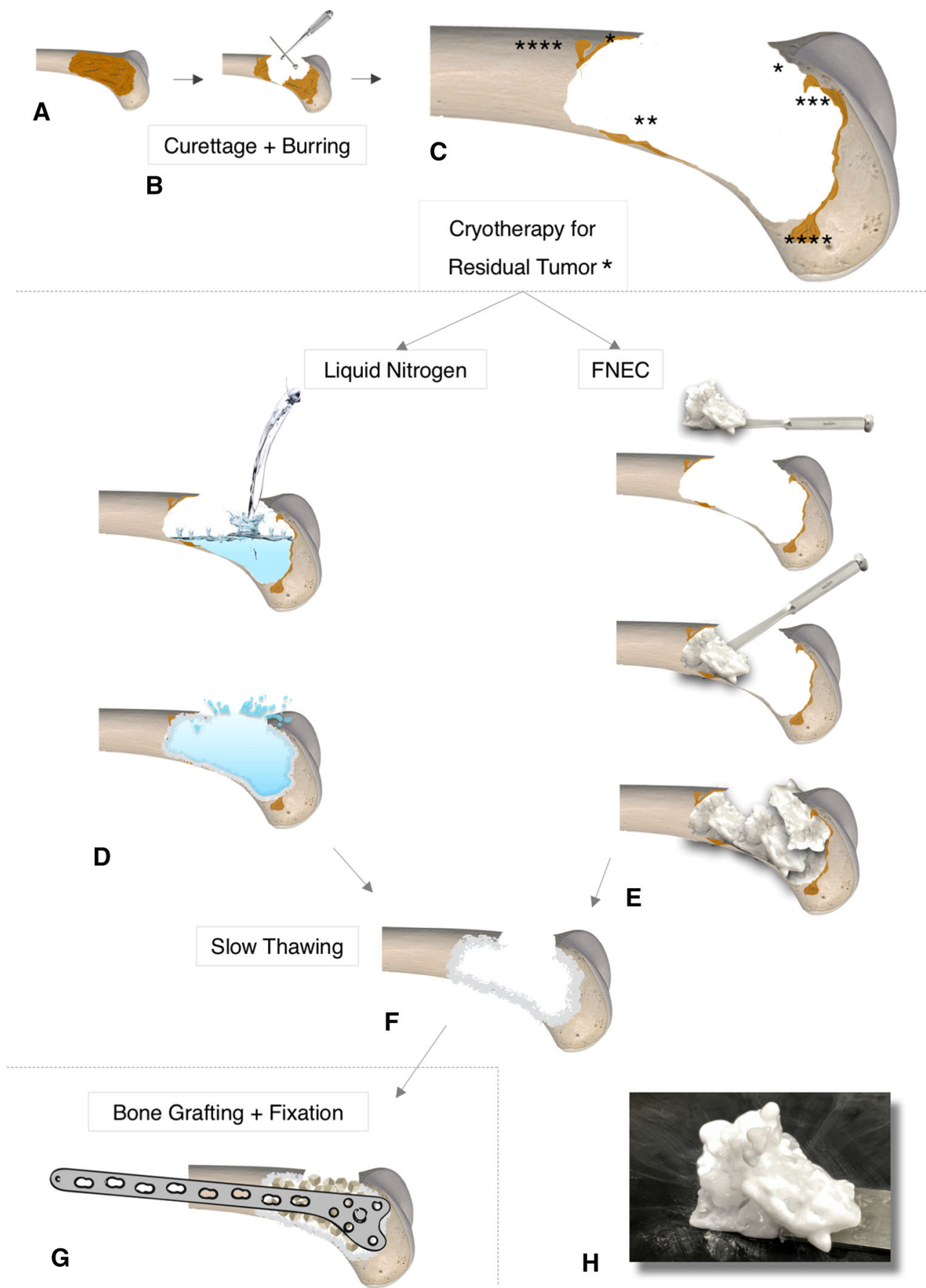

the chicken chorioallantoic membrane, and then treated them with liquid nitrogen or freezing nitrogen ethanol composite. Primary GCT stromal cells were obtained from fresh tissue of five patients with GCT after institutional review board approval and written consent. Cells isolated from the GCT tissue were cultured in the glutamine-containing Dulbecco's Modified Eagle Medium (DMEM, high glucose; Thermo Fisher Scientific, Waltham, MA, USA) supplemented with $10 \%$ fetal bovine serum and $1 \%$ penicillin and streptomycin stock solution (Thermo Fisher
Scientific). After the third successive passage, the multinucleated giant cells were eliminated from the culture. The remaining mesenchymal stromal cells were verified by a senior pathologist $(\mathrm{PCHC})$ on microscopic morphologic evaluation. After multiple passages, the cultured cells were still highly viable and no senescence was shown, which supported the contention that these were tumor cells. Furthermore, the tumorigenicity of the cultured cells was verified by tumor nodule formation successive to a chicken chorioallantoic membrane inoculation. Fertilized eggs 


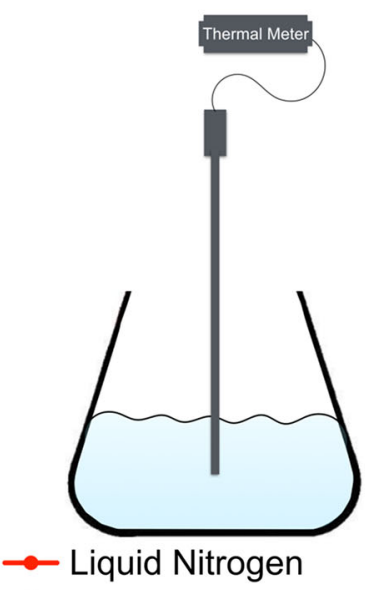

A
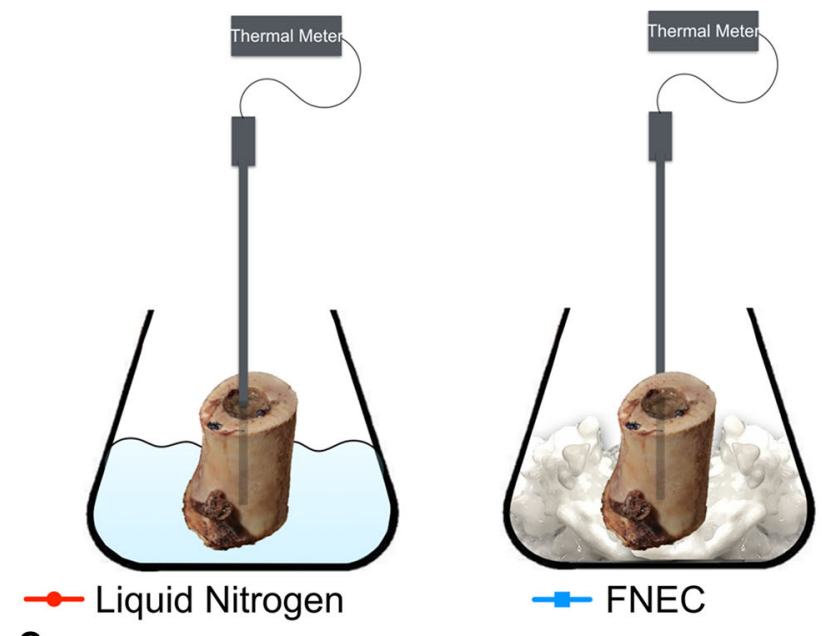

C

Fig. 2A-D (A) The diagram shows placement of thermal meters for liquid nitrogen and freezing nitrogen ethanol composite (FNEC). (B) The curves show cooling for the directly contacting-surface of liquid nitrogen (red) or freezing nitrogen ethanol composite (blue). The reference curve (green) showing the minimal requirement for killing tumor cells was plotted in accordance with the published data [7]. The cooling rate was determined by dividing the temperature difference between room temperature and the target $-60^{\circ} \mathrm{C}$ with the required

acquired from a local commercial hatchery were incubated in an automatic incubator at $37^{\circ} \mathrm{C}$ and minimum $50 \%$ humidity. On Day 11, Matrigel ${ }^{\circledR}$ (Corning Life Sciences, Tewksbury, MA, USA) containing GCT cells $\left(1 \times 10^{6}\right)$ was directly introduced onto the chicken chicken chorioallantoic membrane preparation. On Day 18, the growing histologically confirmed GCT nodules (confirmed by PCHC, data not shown) were collected from the chicken chorioallantoic membrane. A total of 15 of 20 inoculated GCT nodules that were obtained from origin chicken chorioallantoic membrane were randomly divided in three groups ( $\mathrm{n}=5$ for each group) and then separately treated
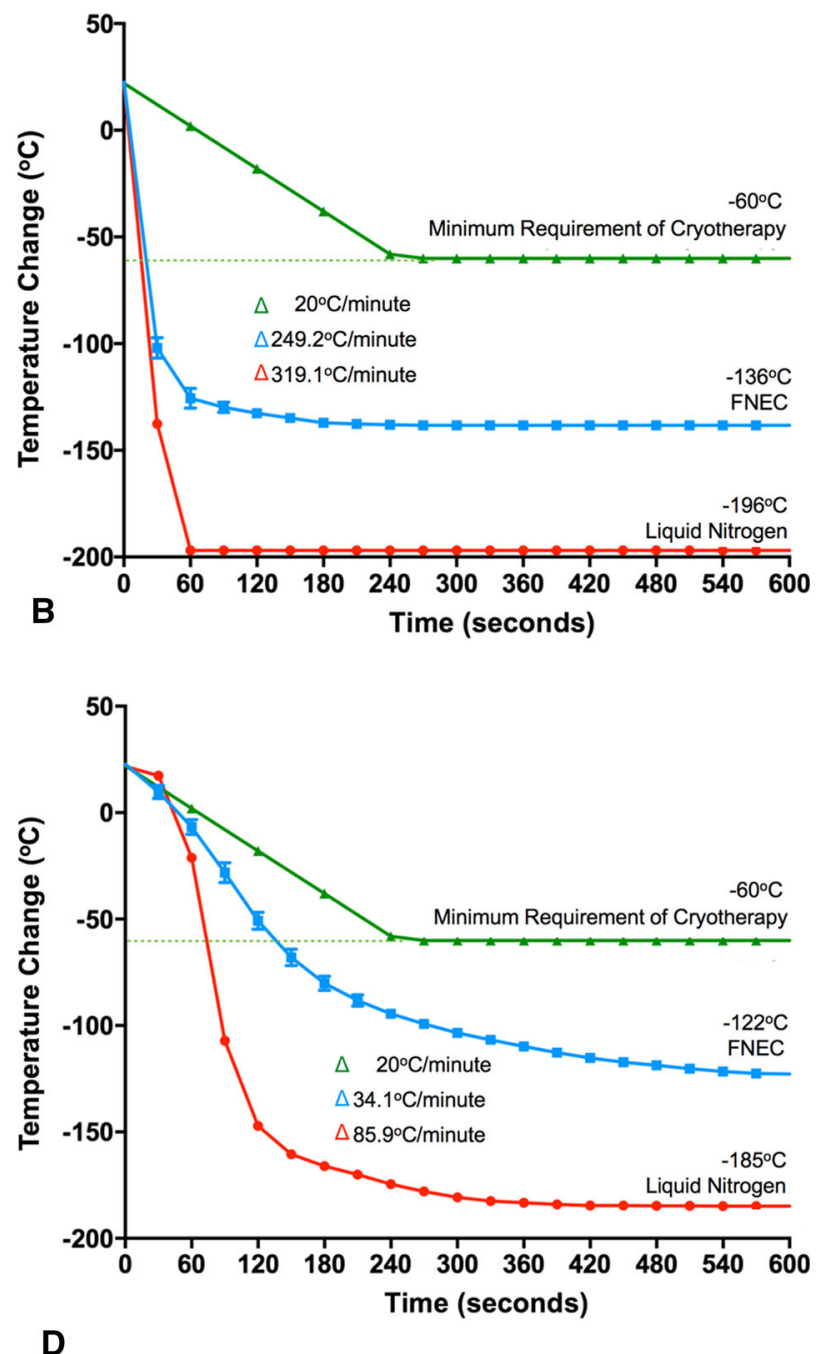

cooling time in minutes. (C) The diagram shows placement of thermal meters inside the bone mass. (D) The curves of the freezing temperature inside the bone cavity of a piece of $10-\mathrm{mm}$ thick porcine femur mediated by liquid nitrogen (red) or freezing nitrogen ethanol composite preparation (blue) are shown. The green curve is the same reference and the cooling rate was calculated with the identical principle described for Illustration B.

with liquid nitrogen or freezing nitrogen ethanol composite for 5 minutes, and the group without treatment was the negative control. Afterward, all 15 GCT grafts were transplanted in separate secondary 11-day chicken chorioallantoic membranes of fertilized chicken eggs. After 7 days incubation, images of the inoculated nodules were photographed and the number of blood vessels in the xenograft tumor was manually calculated for each group. In the end, the tumor graft-bearing chicken chorioallantoic membranes were embedded in paraffin wax and prepared for immunohistochemical analysis. Mouse antihuman nuclei $(\mathrm{HuNu})$ monoclonal antibody (Merck Millipore, 
Darmstadt, Germany) was used as the primary antibody to detect the cells of human origin on the secondary chicken chorioallantoic membrane. Under microscopic observation, the HuNu-positive cells were identified and marked using GraphPad Prism 6 software and then manually counted by three observers (JYW, PCHC, and $\mathrm{SCH}$ ) in a blind manner $(\times 200)$. Intra- and interobserver reliability were measured and found to be consistent. Statistical analysis was performed as previously described.

Between December 2013 and December 2014, three surgeons (P-KW, C-FC, and W-MC) were involved in treating a total of 23 patients with GCT. All the participants were informed about the study before signing an informed consent. We excluded patients with recurrent disease $(\mathrm{n}=3)$, receiving marginal margin resection $(\mathrm{n}=3)$, unwilling to receive freezing nitrogen ethanol composite treatment $(\mathrm{n}=3)$, and with tumors found in an axial location $(n=4)$ and upper limbs $(n=3)$. This left us with seven patients (five males and two females; 23 to 53 years old) who received adjuvant freezing nitrogen ethanol composite cryotherapy. Among the enrolled participants, GCT Grades I to III occurred in the tibia $(\mathrm{n}=5$, two distal and three proximal sites) or the femur $(\mathrm{n}=2$, distal site).

The surgical technique was performed under tourniquet control. After exposure of the involved bone tissue, a cortical window the size of the longest longitudinal dimension of the tumor was made. Gross tumor was removed by hand curettes followed by high-speed burring. Some residual tumor cells may remain. We used a warm water-perfused gauze pad to insulate the normal tissues adjacent to the surgical lesions. The freshly prepared semisolid freezing nitrogen ethanol composite was scooped into the lesion cavity. The exterior surface of the freezing nitrogen ethanol composite preparation may melt faster. The melted freezing nitrogen ethanol composite was removed and additional fresh freezing nitrogen ethanol composite was added to ensure a consistent semisolid status. At least 5 minutes of exposure to freezing nitrogen ethanol composite was ensured for the entire bone cavity. Finally, the freezing nitrogen ethanol composite-treated tissue was thawed for 15 minutes. Reconstruction was conducted using bone grafts and internal fixation as dictated by the nature of the lesions.

At postoperative Day 2, any intraoperative complications such as nerve injury and skin necrosis were recorded. Postoperative partial weightbearing and ROM training were prescribed for all participants. For the followup evaluations, radiographic images were obtained every 6 weeks until bone healing. Limb MR images were acquired at 6-month intervals during the first 2 postoperative years. Local recurrence and any postoperative complications including pathogenic fracture and infection were documented.
The average followup was $24 \pm 4$ months (range, 1930 months), and no patients were lost to followup.

\section{Results}

Freshly prepared freezing nitrogen ethanol composite achieved cooling levels consistent with tumor killing, as reported elsewhere [17, 23, 37], and apoptosis associated with freezing nitrogen ethanol composite treatment was observed in GCT cells, implying cell death. For the freezing nitrogen ethanol composite preparation, the temperature of the freezing nitrogen ethanol composite contact surface decreased to an average $-102^{\circ} \mathrm{C}$ within $30 \mathrm{sec}-$ onds and then toward $-136^{\circ} \mathrm{C}$ at a cooling rate of $-249^{\circ} \mathrm{C}$ per minute (Fig. 2B, blue). The freezing nitrogen ethanol composite froze throughout the bone tissue to $-68^{\circ} \mathrm{C}$ at 150 seconds and to $-122^{\circ} \mathrm{C}$ in 10 minutes (Fig. 2D, blue). Accordingly freezing nitrogen ethanol composite mediates a freezing effect across bone tissue at a cooling rate of $-34^{\circ} \mathrm{C}$ per minute. However, liquid nitrogen conducted a freezing effect through the bone mass at a cooling rate of $-86^{\circ} \mathrm{C}$ per minute and static freezing was achieved at approximately $-185^{\circ} \mathrm{C}$ (Fig. 2B, red). In an ex vivo experiment, the freezing nitrogen ethanol composite revealed similar GCT morphologic changes, revealing cell shrinkage in comparison to that mediated by liquid nitrogen. Compared with the untreated samples, ethanol treatment resulted in cytoplasmic dehydration but the nuclear changes were not seen (Fig. 3A). Diminished cellular volume and expanded intercellular space were observed. Disappearance of intracellular lipid-containing organelles was illustrated by cytoplasmic vacuolation for 5 minutes of ethanol exposure. Edematous and myxoid changes of intercellular stroma in association with disrupted cell membrane and the cell-stroma junction were seen in the 30-second treatment on GCT bones by use of liquid nitrogen. Longer liquid nitrogen incubation caused irregular cell contour and severe disruption of collagenous stroma. The freezing nitrogen ethanol composite preparation also mediated loss of cellular fluid and cytoplasmic vacuolation. Longer freezing nitrogen ethanol composite exposure (5 minutes) resulted in severe edematous and myxoid changes of the stroma and dehydration and vacuolation similar to that produced by liquid nitrogen treatment. Changes in histologic morphologic features showed that liquid nitrogen and freezing nitrogen ethanol composite treatment led to shrinkage in the nuclei of stromal cells and the size of multinucleated osteoclast-like giant cells. Microscopic quantification $(\times 100)$ showed that the proportion of nucleated stromal cells area was decreased at a rate of approximately $24 \%(22 \% \pm 2 \%$ vs $16 \% \pm 2 \% ; \mathrm{p}=0.002$ ) for 30 -second exposure to liquid 


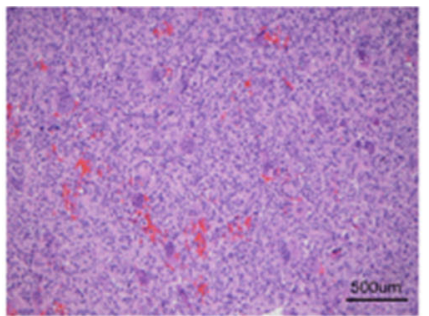

GCT control

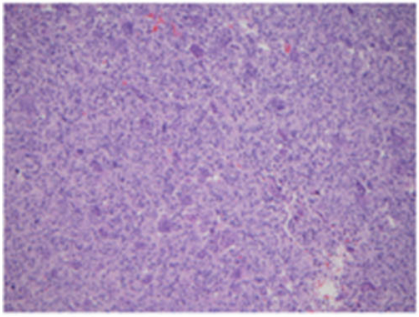

Eth 30 seconds

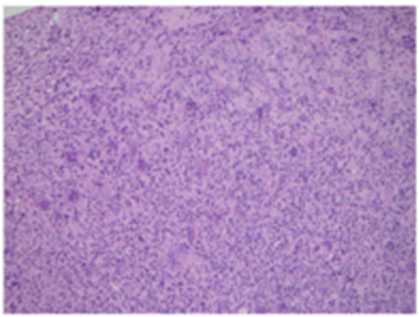

LN 30 seconds

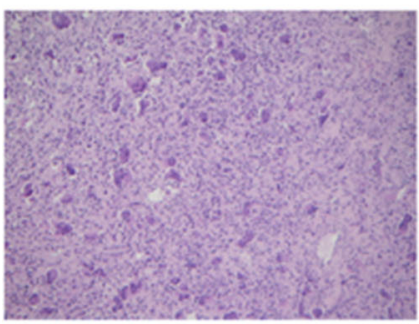

FNEC 30 seconds

A

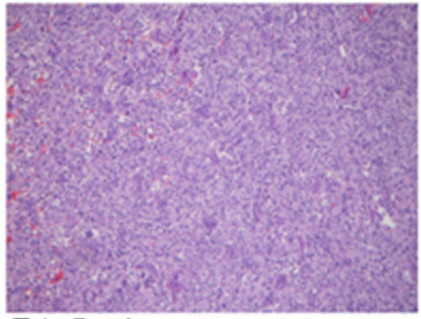

Eth 5 minutes

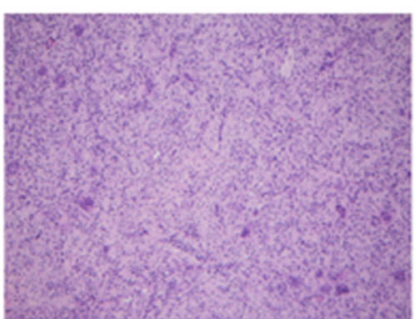

LN 5 minutes

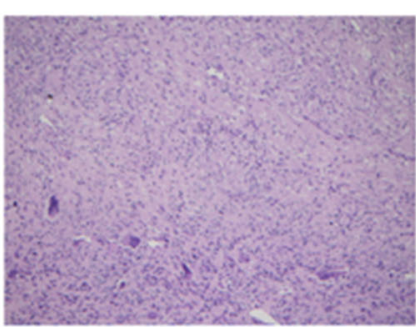

FNEC 5 minutes
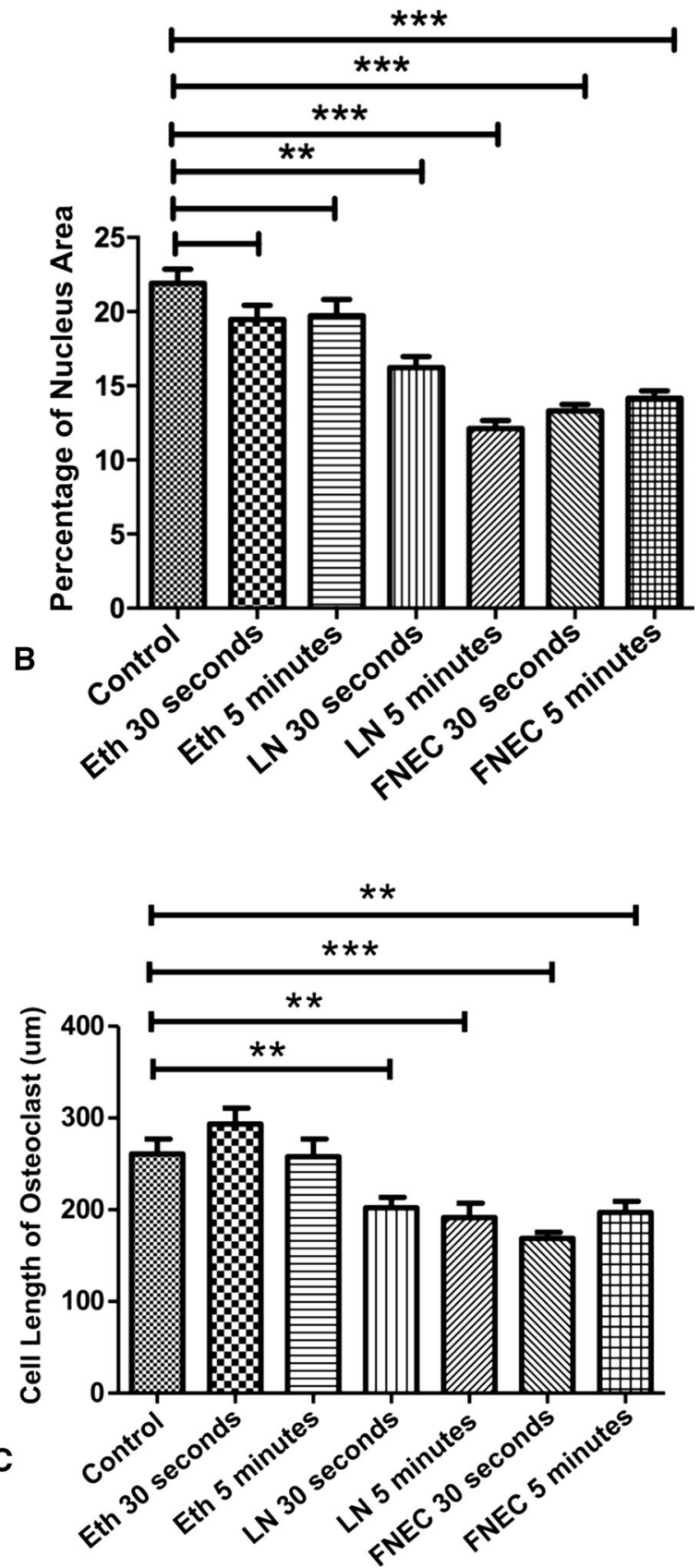

Fig. 3A-C Histologic examination of the cryoablation effect on giant cell tumor (GCT) bone tissue mediated by direct pouring of liquid nitrogen or freezing nitrogen composite preparation is shown. (A) The photomicrographs $(\times 100)$ show the hematoxylin and eosinstained samples for the GCT control and for the pretreated with ethanol (Eth), liquid nitrogen (LN), or freezing nitrogen ethanol composite (FNEC) at 30 seconds and 5 minutes respectively. (B) A bar chart shows the results of quantification on the ratio of the nuclear area of stromal cells to the total area for the hematoxylin and eosin-

nitrogen and it was twice that $(22 \% \pm 2 \%$ vs $12 \% \pm 1 \%$; $\mathrm{p}<0.0001$ ) for the 5-minute exposure (Fig. 3B). However, freezing nitrogen ethanol composite preparation took 30 seconds to achieve a similar effect $(22 \% \pm 2 \%$ vs

stained samples pretreated with ethanol, liquid nitrogen, or freezing nitrogen ethanol composite at 30 seconds and 5 minutes respectively. The microscopic magnification was $\times 200$. **p $<0.01$; ***p $<0.001$ (C) A bar chart shows the results of measurement (magnification $=\times 100$ ) on the cell length of osteoclasts for the hematoxylin and eosin-stained samples pretreated with ethanol, liquid nitrogen, or freezing nitrogen ethanol composite at 30 seconds and 5 minutes respectively. $* * \mathrm{p}<0.01 ; * * * \mathrm{p}<0.001$.

$13 \% \pm 1 \% ; \mathrm{p}<0.0001)$ mediated by directly pouring liquid nitrogen. Likewise, quantification on the cellular length of multinucleated osteoclast-like giant cells showed that liquid nitrogen $(202 \pm 45 \mu \mathrm{m} ; \mathrm{p}=0.006)$ and 
freezing nitrogen ethanol composite $(169 \pm 27 \mu \mathrm{m}$; $\mathrm{p}<0.001)$ mediated more cellular shrinkage for $30 \mathrm{sec}-$ onds of treatment and the effects were sustained to 5 minutes of exposure (Fig. 3C). The ethanol treatment $(258 \pm 85 \mu \mathrm{m} ; \mathrm{p}>0.05)$ did not show a difference compared with untreated cells on the histomorphologic image (Eth, Fig. 3C) at 5 minutes. Liquid nitrogen and freezing nitrogen ethanol composite resulted in apoptosis of GCT cells at 5 minutes $(\times 400$, liquid nitrogen, $100 \pm 21$ TUNEL positive cells, $\mathrm{p}<0.0001$; freezing nitrogen ethanol composite, $95 \pm 13$ TUNEL positive cells, $\mathrm{p}<0.0001)$ compared with the control and ethanol treatment groups (Fig. 4A-B). Freezing nitrogen ethanol composite caused a greater level of apoptosis $(\times 400$; $42 \pm 7$ TUNEL-positive cells; $p<0.0001$ ) compared with liquid nitrogen $(x 400 ; 77 \pm 11$ TUNEL- positive cells; $\mathrm{p}<0.0001$ ) at 30 seconds (Fig. 4B). Western blotting analysis showed changes in the level of apoptosis-regulating proteins after the treatment with liquid nitrogen and freezing nitrogen ethanol composite but not with the ethanol treatment (Fig. 4C). Densitometric quantification on images also showed that three cleaved enzymes, caspases 3, 8, and 9, involved in apoptosis activation were increased in liquid nitrogen (caspase 3, 333\% $\pm 79 \%$, $\mathrm{p}=0.015$; caspase $8,223 \% \pm 91 \%, \mathrm{p}=0.092$; caspase 9 , $320 \% \pm 99 \%, \mathrm{p}=0.027)$ and freezing nitrogen ethanol composite (caspase $3,342 \% \pm 18 \%, \mathrm{p}=0.002$; caspase 8 , $359 \% \pm 48 \%, \mathrm{p}=0.002 ;$ caspase $9,237 \% \pm 52 \%$, $\mathrm{p}=0.032$ ) treatment groups at 30 seconds compared with the untreated control (Fig. 4D). The longer exposure (5 minutes) to either liquid nitrogen $(529 \% \pm 102 \%$; $\mathrm{p}=0.003)$ or freezing nitrogen ethanol composite $(546 \% \pm 54 \% ; \mathrm{p}<0.001)$ led to a higher level of cleaved caspase 3. However, freezing nitrogen ethanol composite treatment resulted in greater levels of elevation of cleaved caspase $8(443 \% \pm 89 \%$ vs $322 \% \pm 111 \%)$ than that of liquid nitrogen at 5 minutes (Fig. 4D). In addition, liquid nitrogen $(289 \% \pm 83 \% ; \mathrm{p}=0.021)$ and freezing nitrogen ethanol composite-treated $(260 \% \pm 32 \% ; \mathrm{p}=0.003) \mathrm{GCT}$ tissues showed an enhanced ratio of $\mathrm{Bax} / \mathrm{Bcl} 2$ at $30 \mathrm{sec}-$ onds (Fig. 4D). Ethanol did not show an effect on the level of the three analyzed caspases.

Progression of grafted human GCT grown in the chicken chorioallantoic membrane was inhibited by freezing nitrogen ethanol composite treatment (Fig. 5A). In this study, the counted number of blood vessels showed that liquid nitrogen (mean, 2; range, $1-4 ; \mathrm{p}<0.001$ ) and freezing nitrogen ethanol composite treatments (mean, 2; range, $1-3 ; p=0.04$ ) for 5 minutes inhibited the neovascularization induced by the untreated GCT (mean, 8; range, 7-12) in the chicken chorioallantoic membrane experiment (Fig. 5B-C). Quantitation on the HuNu-positive cells showed a higher amount of human-origin tumor $(\mathrm{HuNu}-$
Fig. 4A-D DNA fragmentation and apoptosis in giant cell tumor (GCT) cells mediated by direct pouring of liquid nitrogen or freezing nitrogen ethanol composite are shown. (A) The photomicrographs show the results for TUNEL staining in situ for the Control, and for the ethanol (Eth), liquid nitrogen (LN), and freezing nitrogen ethanol composite (FNEC) samples at 30 seconds and 5 minutes. (B) A bar chart shows the results of TNUEL-positive cell counts. ***p $<0.001$. (C) Western blotting analysis showed the changes in the regulatory proteins involved in the apoptotic signal cascade. (D) A bar chart shows the results of densitometric quantification on the signal strength for the results of the Western blotting assay. Eth = ethanol; $\mathrm{LN}=$ liquid nitrogen; FNEC $=$ freezing nitrogen ethanol composite; $* \mathrm{p}<0.05 ; * * \mathrm{p}<0.01$, and $* * * \mathrm{p}<0.001$.

positive) cells in the secondary chicken chorioallantoic membrane of negative controls (mean, 487; range, 361-641) than that of liquid nitrogen (mean, 50; range, $26-78 ; \mathrm{p}<0.0001)$ and freezing nitrogen ethanol composite (mean, 45; range, 30-60; $\mathrm{p}<0.0001$ ) treatment (Fig. 5D-E).

Preliminary clinical evaluation found no local recurrences, and no intra- or postoperative complications such as nerve injury, skin necrosis, or pathologic fractures that might be attributed to the freezing nitrogen ethanol composite treatment (Table 1). Radiographic images are shown for a representative 23-year-old male patient with GCT (Fig. 6) who underwent intralesional excision and adjuvant cryotherapy by freezing nitrogen ethanol composite cryotherapy.

\section{Discussion}

GCT of bone has a prevalence of $20 \%$ of benign bone tumors in the US population [31]. Intralesional curettage is considered a standard treatment of GCT, however, local recurrence has been reported to occur after curettage in $40 \%-50 \%$ of patients so treated compared with those who have en bloc excision $(<20 \%)$ [31]. In conjunction with adjuvant cryotherapy such as the use of liquid nitrogen, the incidence of local recurrence has been reported to be lower $(0 \%-3.2 \%)[33,38]$. Despite its advantages of being cost effective and easy to implement, the recommended extreme freezing temperatures of $-196^{\circ} \mathrm{C}$ reached by direct pouring of liquid nitrogen into the cavity after curettage has been associated with complications such as bone fracture [35]. In addition, severe evaporation occurs during the pouring procedures which increases the risk of coolant spillage that could lead to skin necrosis. Therefore, an effective freezing agent exhibiting a mild endothermic property and a higher viscosity could be advantageous by delivering the required freezing temperatures and reducing the complication rate. In the current study, a novel semisolid composite easily prepared by mixing ethanol and liquid nitrogen was used. Its use showed effective tumor- 


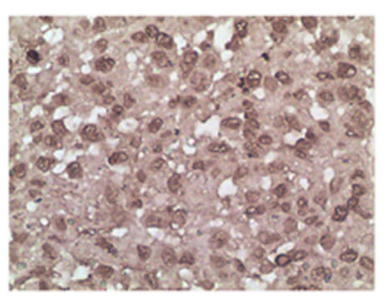

GCT Positive Control

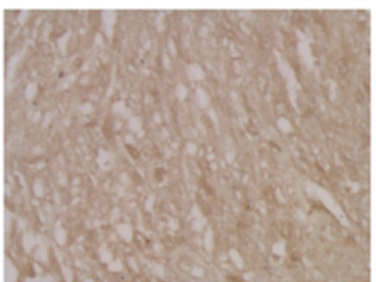

Eth 30 seconds

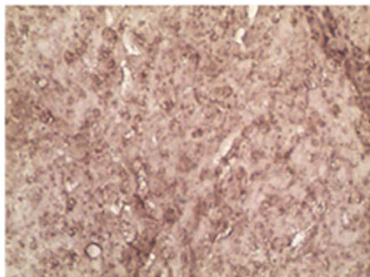

LN 30 seconds

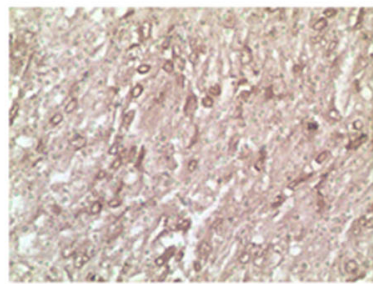

FNEC 30 seconds

A

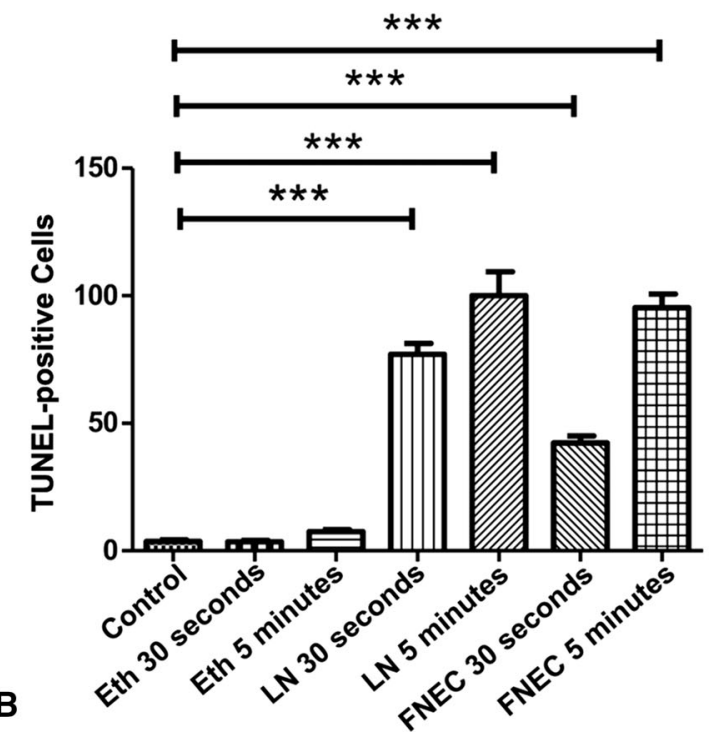

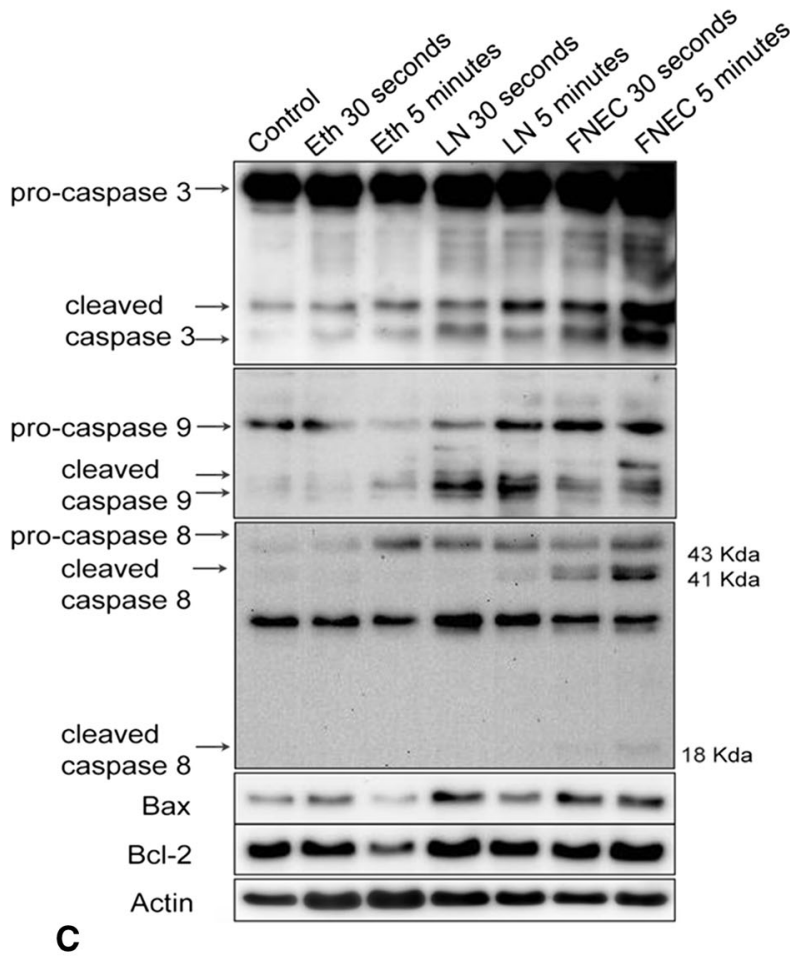

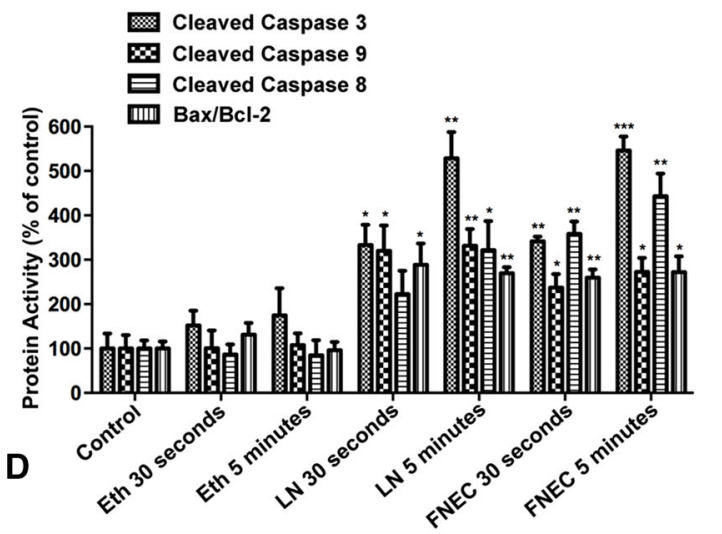


Fig. 5A-E The results of the investigation using a chicken chorioallantoic membrane (CAM) model are shown for the effect of liquid nitrogen (LN) or freezing nitrogen ethanol composite (FNEC) on tumor neovascularization and the giant cell tumor (GCT) neoplasm in vivo. (A) The diagram illustrates the experimental procedures to transplant and grow the GCT grafts on a chicken chorioallantoic membrane preparation. (B) The photographs show the growing tumor nodules in association with neovascularization. (C) A bar chart shows the results of quantitation on blood vessels for the secondary chicken chorioallantoic membrane-bearing GCT xenografts among the three experiment groups. $* * * \mathrm{p}<0.001$. (D) The photographs show the results of immunohistochemical staining, and (E) the bar chart shows the results of quantitation on the $\mathrm{HuNu}$-positive human-origin tumor cells on the secondary chicken chorioallantoic membrane-bearing GCT xenografts among the three experiment groups. $* * * \mathrm{p}<0.001$.

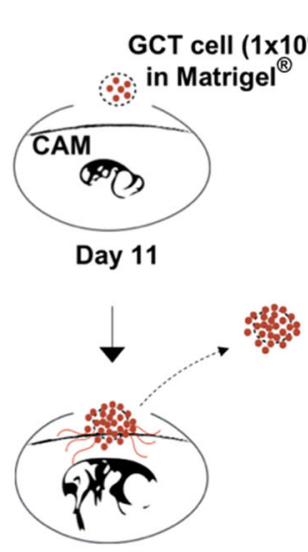

Day 18

A

B

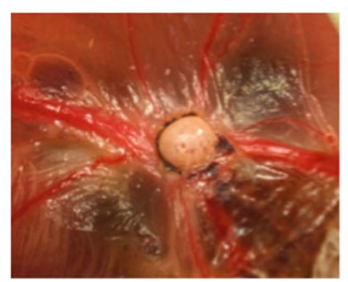

Secondary CAM

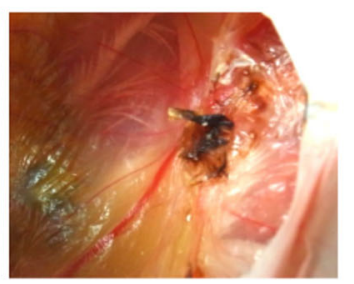

C
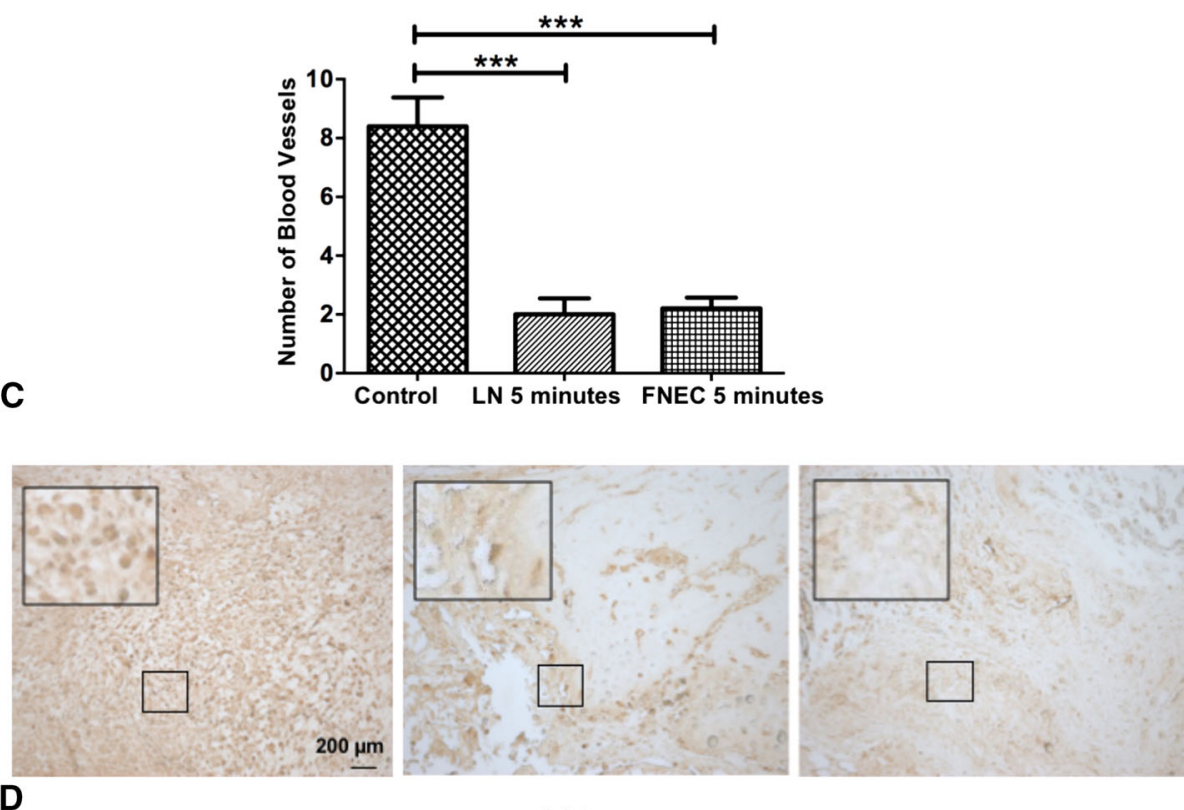

D

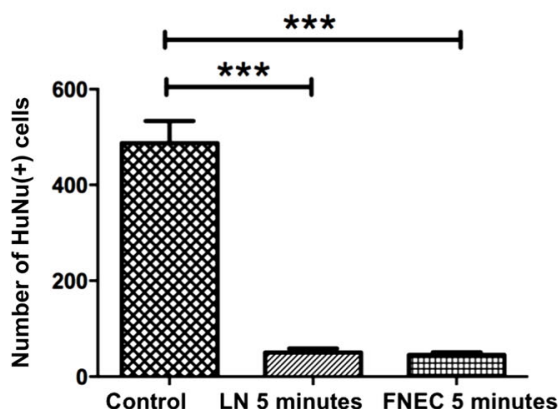


Table 1. Patient demographics, tumor characteristics, and outcomes

\begin{tabular}{|c|c|c|c|c|c|c|c|c|c|c|}
\hline $\begin{array}{l}\text { Patient } \\
\text { number }\end{array}$ & Gender & $\begin{array}{l}\text { Age } \\
\text { (years) }\end{array}$ & $\begin{array}{l}\text { Campanacci } \\
\text { grade }\end{array}$ & Tumor location & $\begin{array}{l}\text { Intraoperative } \\
\text { nerve injury }\end{array}$ & $\begin{array}{l}\text { Intraoperative } \\
\text { skin necrosis }\end{array}$ & Fracture & Infection & $\begin{array}{l}\text { Local } \\
\text { recurrence }\end{array}$ & $\begin{array}{l}\text { Followup } \\
\text { (months) }\end{array}$ \\
\hline 1 & M & 49 & II & Distal tibia & No & No & No & No & No & 30 \\
\hline 2 & M & 23 & III & Distal femur & No & No & No & No & No & 28 \\
\hline 3 & $\mathrm{~F}$ & 40 & I & Proximal tibia & No & No & No & No & No & 27 \\
\hline 4 & $\mathrm{~F}$ & 36 & II & Proximal tibia & No & No & No & No & No & 23 \\
\hline 5 & M & 44 & III & Distal femur & No & No & No & No & No & 22 \\
\hline 6 & M & 53 & II & Distal tibia & No & No & No & No & No & 20 \\
\hline 7 & M & 31 & II & Proximal tibia & No & No & No & No & No & 19 \\
\hline
\end{tabular}

$\mathrm{M}=$ male; $\mathrm{F}=$ female.

eradicating activity by achieving the desired freezing temperature and cooling rate in ex vivo and in vivo experiment models. A small series in a case-controlled pilot clinical study and short-term followup also provided supportive results for further clinical studies on a larger scale.

Several limitations for this study need to be addressed. Regardless of the liquid phase or semisolid coolant, gravity dependence needs to be considered. Vaporized liquid nitrogen spray could be an option to eliminate the concern. In practice, however, it is time consuming to achieve homogeneous distribution of the freezing effect for a larger surgical lesion. In addition, gas embolism has been reported in patients with GCT receiving liquid nitrogen spray [37]. In particular, the risk is greater if the tumor is located in an area with high vascularization such as the metaphysis of long bones [36]. Owing to the absence of available markers for the specific identification on human GCT cells, we did not have definitive evidence to confirm that the primary cultures were GCT cells. However, we did our best to verify the cell morphology by a senior pathologist's evaluation and show that they grew tumors when reinjected after passage. Unlike fibroblasts, the cultured human GCT cells retained tumor cell-like highly proliferative capacity. Furthermore, the passaged primary culture was transplanted to chicken chorioallantoic membrane and then progressed to tumor nodules that were further verified by histologic evaluation. Patients in this study were restricted to those with lower extremity lesions, such as in the distal femur and proximal tibia, where a pneumatic tourniquet was applied for the surgical procedures. However we have not yet included patients with GCT occurring at other locations such as the proximal humerus, sacrum, and proximal femur where a tourniquet cannot be applied. Therefore the use of this method probably is restricted by the location of the GCT in selected patients. In the ex vivo experiment models, we were not able to simulate the physiologic conditions under surgery such as blood flow, body temperature, and connected soft tissues that may affect freezing being conducted. It could be a critical factor related to the tumor-killing efficacy and local recurrence. However, previous studies have shown a low recurrence rate in patients with GCT treated with liquid nitrogen $[22,23]$. Our ex vivo and in vivo animal experiment data showed no difference in tumor effects measured between the use of liquid nitrogen and freezing nitrogen ethanol composite. Therefore the effect of the physiologic condition in surgical procedures is likely minimized. For the in vivo clinical evaluation, the quality of evidence was limited by the small number of participants and absence of control subjects. Furthermore, the duration of the followup, an average of 24 months, may not be long enough to cover late fracture and tumor recurrence. However, a previous study showed that the median duration of local recurrence was 23.1 months among 19 patients with GCT [30]. Evaluation of the occurrence of perioperative complications was not limited by the duration of followup. However, a prospective clinical study design in larger cohorts and longer followup are required for further study.

Freezing nitrogen ethanol composite appears to effectively kill GCT cells similar to that mediated by liquid nitrogen. Our results showed a freezing rate of $-249^{\circ} \mathrm{C}$ per minute on the surface immediately contacting the freezing nitrogen ethanol composite while the freezing rate was $-34^{\circ} \mathrm{C}$ per minute for freezing throughout a $10-\mathrm{mm}$ thick bone mass. Apparently freezing nitrogen ethanol composite fulfills the criteria of freezing rate (minimum $-20^{\circ} \mathrm{C}$ per minute) for tumor cryoablation [5]. In addition to the target freezing temperature, the freezing and thawing rates are critical for effective cryoablation [1, 7, 8]. Rapid freezing and slow thawing mediate intracellular ice crystallization and recrystallization generating shear stress on tumor cells. The recommended freezing rate is greater than $-20^{\circ} \mathrm{C}$ per minute and a rate less than $10^{\circ} \mathrm{C}$ per minute is suitable for thawing [7, 8, 12]. We identified the involvement of apoptosis in the frozen GCT tissues. Cryoablationmediated changes in apoptosis and morphologic features of tumor cells were compared between treatments of freezing nitrogen ethanol composite and liquid nitrogen. In this 

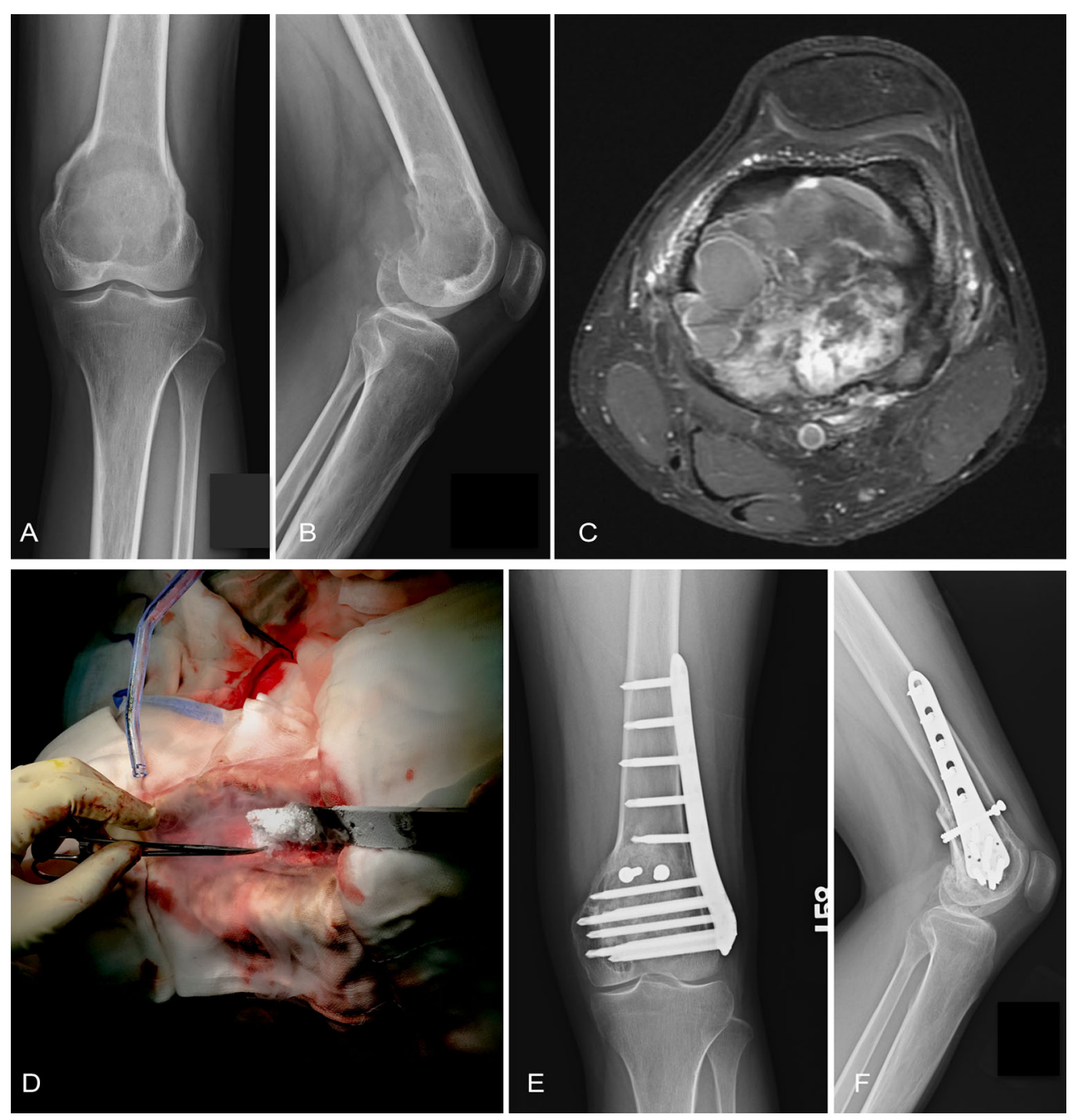

Fig. 6A-F A 23-year-old man with a diagnosis of GCT underwent intralesional excision and adjuvant treatment by freezing nitrogen ethanol composite cryotherapy. Preoperative (A) posteroanterior and (B) lateral view radiographs show an expansile, osteolytic lesion located at the distal femur with epiphyseal invasion and cortical breakthrough. (C) The T1 fat-saturated postcontrast MR image shows soft tissue expansion toward the posterior aspect and attached to the

study, 5-minute freezing nitrogen ethanol composite treatment achieved comparable effects on morphologic shrinkage of osteoclast-like giant cells and the neoplastic stromal cells compared with that of liquid nitrogen. Histopathologic evaluation of a GCT section showed mononuclear, ovoid, or short spindle-like neoplastic stromal cells frequently mixing with large multinuclear osteoclast-like giant cells. The high incidence of recurrence after surgical removal likely results from residual stromal cells [9]. Accordingly, we adopted a 5-minute exposure to freezing nitrogen ethanol composite for the patients treated in this study.

Regarding the regulatory molecules in the apoptotic signaling cascade, we observed consistent evidence that popliteal vessels. (D) A photograph shows application of the freezing nitrogen ethanol composite. A warm water-perfused gauze pad was applied to insulate the normal tissues adjacent to the surgical lesions. (E) After 18 months followup, the (E) postoperative posteroanterior and (F) lateral view radiographs show good bone incorporation and no local recurrence.

liquid nitrogen and freezing nitrogen ethanol composite mediated a substantial increase in the cleaved active caspases 3, 8, and 9 compared with that of the untreated control. DNA fragmentation and apoptosis were identified as a mechanism leading to cell death in cryotherapy-treated prostate and colorectal cancers [6] but have not been found in frozen bone tumors. However, the involvement of cascade proteocleaved activation of factors including caspases 3 , 8, and 9 has been shown in the apoptotic signaling pathway of bone cells [25]. The molecular aspects related to DNA fragmentation are consistent with the quantitative TUNEL assays in situ. Activation of caspase 8 is mediated by cellular death ligands (FasL/TRAIL) (extrinsic pathway), whereas Bcl 2 family proteins regulate the expression 
of active caspase 9 (intrinsic pathway) [25]. Active caspases 8 and 9 induce elevation of effector caspase 3 and consequently lead to cell death characterized by morphologic and biochemical alterations [25]. The results of our study suggested that extrinsic and intrinsic apoptosis pathways are involved in freezing nitrogen ethanol composite- and liquid nitrogen-mediated cryoablation. In addition, the ratio of $\mathrm{Bax} / \mathrm{Bcl} 2$ was substantially enhanced in the freezing nitrogen ethanol composite and liquid nitrogen treatment groups. It has been reported that the expression ratio of $\mathrm{Bax} / \mathrm{Bcl} 2$ positively correlates to the apoptotic rate in the cryoablation-injured human colorectal cancer cells [40].

In this study, we showed that freezing nitrogen ethanol composite treatment exhibits a comparable effect to liquid nitrogen on inhibiting neovascularization and tumor growth derived from GCT xenografts. Transplanted GCT grafts growing in chicken chorioallantoic membrane of a fertilized egg have been used as a reliable in vivo model for investigation of angiogenesis and metastasis of GCT $[3,16,34,39]$.

As a preliminary attempt to see if our in vitro and ex vivo results would be useful in the clinical setting, we used adjuvant freezing nitrogen ethanol composite in the treatment of a small group of patients with GCT to evaluate the operational convenience and safety during surgery. In these seven patients, neither intraoperative complications such as neurovascular injuries and skin necrosis nor infection were observed. Additionally, there was no pathologic fracture or local recurrence during followup. We did not have a direct comparison group with an adjuvant or with standard liquid nitrogen application. Larger, comparative studies will be needed to confirm our preliminary findings and comment in greater detail regarding differences in safety among the available approaches.

Freezing nitrogen ethanol composite is a semisolid phase cryotherapy application that appears to offer appropriate thermal conduction and comparable ex vivo and in vivo GCT cryoablation compared with standard approaches of liquid nitrogen application. We also present preliminary clinical evidence that freezing nitrogen ethanol composite provides a convenient method of freezing during curettage procedures for GCT of the extremity. If confirmed in larger studies, this application of adjuvant cryotherapy might be considered in the treatment of benign aggressive or low-grade bone tumors such as GCT.

\section{References}

1. Arbeitsgemeinschaft Knochentumoren, Becker WT, Dohle J, Bernd L, Braun A, Cserhati M, Enderle A, Hovy L, Matejovsky Z, Szendroi M, Trieb K, Tunn PU. Local recurrence of giant cell tumor of bone after intralesional treatment with and without adjuvant therapy. J Bone Joint Surg Am. 2008;90:1060-1067.

2. Amanatullah DF, Clark TR, Lopez MJ, Borys D, Tamurian RM. Giant cell tumor of bone. Orthopedics. 2014;37:112-120.

3. Balke M, Neumann A, Szuhai K, Agelopoulos K, August C, Gosheger G, Hogendoorn PC, Athanasou N, Buerger H, Hagedorn M. A short-term in vivo model for giant cell tumor of bone. BMC Cancer. 2011;11:241.

4. Balke M, Schremper L, Gebert C, Ahrens H, Streitbuerger A, Koehler G, Hardes J, Gosheger G. Giant cell tumor of bone: treatment and outcome of 214 cases. J Cancer Res Clin Oncol. 2008;134:969-978.

5. Baust JG, Gage AA. The molecular basis of cryosurgery. BJU Int. 2005;95:1187-1191.

6. Baust JG, Gage AA, Clarke D, Baust JM, Van Buskirk R. Cryosurgery: a putative approach to molecular-based optimization. Cryobiology. 2004;48:190-204.

7. Bischof J, Christov K, Rubinsky B. A morphological study of cooling rate response in normal and neoplastic human liver tissue: cryosurgical implications. Cryobiology. 1993;30:482-492.

8. Bischof JC, Smith D, Pazhayannur PV, Manivel C, Hulbert J, Roberts KP. Cryosurgery of Dunning AT-1 rat prostate tumor: thermal, biophysical, and viability response at the cellular and tissue level. Cryobiology. 1997;34:42-69.

9. Dabak N, Tomak Y, Piskin A, Gulman B, Ozcan H. Early results of a modified technique of cryosurgery. Int Orthop. 2003;27:249253.

10. Durr HR, Maier M, Jansson V, Baur A, Refior HJ. Phenol as an adjuvant for local control in the treatment of giant cell tumour of the bone. Eur J Surg Oncol. 1999;25:610-618.

11. Fong EL, Watson BM, Kasper FK, Mikos AG. Building bridges: leveraging interdisciplinary collaborations in the development of biomaterials to meet clinical needs. Adv Mater. 2012;24:49955013

12. Gage AA, Baust JM, Baust JG. Experimental cryosurgery investigations in vivo. Cryobiology. 2009;59:229-243.

13. Kawano M, Nishida H, Nakamoto $Y$, Tsumura $H$, Tsuchiya $H$. Cryoimmunologic antitumor effects enhanced by dendritic cells in osteosarcoma. Clin Orthop Relat Res. 2010;468:1373-1383.

14. Klenke FM, Wenger DE, Inwards CY, Rose PS, Sim FH. Giant cell tumor of bone: risk factors for recurrence. Clin Orthop Relat Res. 2011;469:591-599.

15. Kremen TJ Jr, Bernthal NM, Eckardt MA, Eckardt JJ. Giant cell tumor of bone: are we stratifying results appropriately? Clin Orthop Relat Res. 2012;470:677-683.

16. Liu L, Aleksandrowicz E, Fan P, Schonsiegel F, Zhang Y, Sahr H, Gladkich J, Mattern J, Depeweg D, Lehner B, Fellenberg J, Herr I. Enrichment of c-Met+ tumorigenic stromal cells of giant cell tumor of bone and targeting by cabozantinib. Cell Death Dis. 2014;5:e1471.

17. Marcove RC. A 17-year review of cryosurgery in the treatment of bone tumors. Clin Orthop Relat Res. 1982;163:231-234.

18. Marcove RC, Miller TR. Treatment of primary and metastatic bone tumors by cryosurgery. JAMA. 1969;207:1890-1894.

19. Marcove RC, Weis LD, Vaghaiwalla MR, Pearson R. Cryosurgery in the treatment of giant cell tumors of bone: a report of 52 consecutive cases. Clin Orthop Relat Res. 1978;134:275-289.

20. Matsubara H, Tsuchiya H, Sakurakichi K, Yamashiro T, Watanabe K, Tomita K. Distraction osteogenesis of a previously irradiated femur with malignant lymphoma: a case report. $J$ Orthop Sci. 2005;10:430-435.

21. McFerrin HE, Olson SD, Gutschow MV, Semon JA, Sullivan DE, Prockop DJ. Rapidly self-renewing human multipotent marrow stromal cells (hMSC) express sialyl Lewis X and actively adhere to arterial endothelium in a chick embryo model system. PLos One. 2014;9:e105411. 
22. Meftah M, Schult P, Henshaw RM. Long-term results of intralesional curettage and cryosurgery for treatment of low-grade chondrosarcoma. J Bone Joint Surg Am. 2013;95:1358-1364.

23. Meller I, Weinbroum A, Bickels J, Dadia S, Nirkin A, Merimsky O, Issakov J, Flusser G, Marouani N, Cohen N, Kollender Y. Fifteen years of bone tumor cryosurgery: a single-center experience of 440 procedures and long-term follow-up. Eur J Surg Oncol. 2008;34:921-927.

24. Mittag F, Leichtle C, Kieckbusch I, Wolburg H, Rudert M, Kluba $\mathrm{T}$, Leichtle U. Cytotoxic effect and tissue penetration of phenol for adjuvant treatment of giant cell tumours. Oncol Lett. 2013;5:1595-1598.

25. Mollazadeh S, Fazly Bazzaz BS, Kerachian MA. Role of apoptosis in pathogenesis and treatment of bone-related diseases. $J$ Orthop Surg Res. 2015;10:15.

26. Muppidi J, Porter M, Siegel RM. Measurement of apoptosis and other forms of cell death. Current Protoc Immunol. 2004; Chapter 3:17. doi: 10.1002/0471142735.im0317s59.

27. Nishida H, Tsuchiya H, Tomita K. Re-implantation of tumour tissue treated by cryotreatment with liquid nitrogen induces antitumour activity against murine osteosarcoma. J Bone Joint Surg Br. 2008;90:1249-1255.

28. Raskin KA, Schwab JH, Mankin HJ, Springfield DS, Hornicek FJ. Giant cell tumor of bone. J Am Acad Orthop Surg. 2013;21:118-126.

29. Rose PS, Morris JM. Cryosurgery/cryoablation in musculoskeletal neoplasms: history and state of the art. Curr Rev Musculoskelet Med. 2015;8:353-360.

30. Siddiqui MA, Seng C, Tan MH. Risk factors for recurrence of giant cell tumours of bone. J Orthop Surg (Hong Kong). 2014;22:108-110.

31. Skubitz KM. Giant cell tumor of bone: current treatment options. Curr Treat Options Oncol. 2014;15:507-518.

32. Song D, Meng T, Xu W, Hou T, Lin Z, Yin H, Li B, Zhou L, Wang T, Han S, Fan T, Miao W, Liu M, Luo J, Zhou W, Li Z,
Xiao J. 5-Fluoruracil blocked giant cell tumor progression by suppressing osteoclastogenesis through NF-kappaB signals and blocking angiogenesis Bone. 2015;78:46-54.

33. Souna BS, Belot N, Duval H, Langlais F, Thomazeau H. No recurrences in selected patients after curettage with cryotherapy for grade I chondrosarcomas. Clin Orthop Relat Res. 2010; 468:1956-1962.

34. Sys G, Van Bockstal M, Forsyth R, Balke M, Poffyn B, Uyttendaele D, Bracke M, De Wever O. Tumor grafts derived from sarcoma patients retain tumor morphology, viability, and invasion potential and indicate disease outcomes in the chick chorioallantoic membrane model. Cancer Lett. 2012; 326:69-78.

35. van der Geest IC, van Noort MP, Shreuder HW, Pruszczynski M, de Rooy JW, Veth RP. The cryosurgical treatment of chondroblastoma of bone: long term oncologic and functional results. $J$ Surg Oncol. 2007;96:230-234.

36. van der Heijden L, Dijkstra PD, van de Sande MA, Kroep JR, Nout RA, van Rijswijk CS, Bovee JV, Hogendoorn PC, Gelderblom $\mathrm{H}$. The clinical approach toward giant cell tumor of bone. Oncologist. 2014;19:550-561.

37. Veth R, Schreuder B, van Beem H, Pruszczynski M, de Rooy J. Cryosurgery in aggressive, benign, and low-grade malignant bone tumours. Lancet Oncol. 2005;6:25-34.

38. Wang EH, Marfori ML, Serrano MV, Rubio DA. Is curettage and high-speed burring sufficient treatment for aneurysmal bone cysts? Clin Orthop Relat Res. 2014;472:3483-3488.

39. Wang CS, Wu PK, Chen CF, Chen WM, Liu CL, Chen TH. Bone-prosthesis composite with rotating hinged-knee prosthesis in limb salvage surgery for high-grade sarcoma around the knee. J Arthroplasty. 2015;30:90-94.

40. Yang WL, Addona T, Nair DG, Qi L, Ravikumar TS. Apoptosis induced by cryo-injury in human colorectal cancer cells is associated with mitochondrial dysfunction. Int J Cancer. 2003; 103:360-369. 